Wu Q, Xie X, Wang Y, Roskilly AP.

Effect of carbon coated aluminum nanoparticles as additive to biodieseldiesel blends on performance and emission characteristics of diesel engine. Applied Energy 2018, 221, 597-604.

\section{Copyright:}

(C) 2018. This manuscript version is made available under the CC-BY-NC-ND 4.0 license

DOI link to article:

https://doi.org/10.1016/i.apenergy.2018.03.157

Date deposited:

$17 / 04 / 2018$

Embargo release date:

17 April 2019

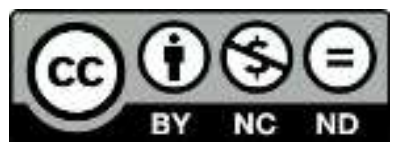

This work is licensed under a

Creative Commons Attribution-NonCommercial-NoDerivatives 4.0 International licence 


\title{
Effect of carbon coated aluminum nanoparticles as additive to biodiesel-diesel blends on performance and emission characteristics of diesel engine
}

\author{
Qibai $\mathrm{Wu}^{\mathrm{a}, \mathrm{b}}$, Xialin Xie ${ }^{\mathrm{a}}$, Yaodong Wang ${ }^{\mathrm{a}, *}$, Tony Roskilly $^{\mathrm{a}}$ \\ ${ }^{a}$ Sir Joseph Swan Centre for Energy Research, Newcastle University, Newcastle NE1 7RU, UK \\ ${ }^{b}$ School of Materials and Energy, Guangdong University of Technology, Guangzhou, 510006, China
}

\begin{abstract}
This study investigates the effects of carbon coated aluminum ( $\mathrm{Al} @ \mathrm{C}$ ) nanoparticles added to diesel-biodiesel blends as additives on engine performance and emissions. The $\mathrm{Al} @ \mathrm{C}$ nanoparticles are added into the diesel-biodiesel fuel in the mass fractions of $30 \mathrm{ppm}$ under ultrasonic mixing. The experimental tests are conducted using a Cummins diesel engine. For comparison, three kinds of fuels including diesel-biodiesel blend (B10), B10 with 4\% ethanol (B10E4), and $\mathrm{B} 10$ with $4 \%$ ethanol and 30-ppm nanoparticles (B10E4N30) are used for the tests under the European Stationary Cycle (ESC). The results show clearly that adding Al@C nanoparticles can reduce brake specific fuel consumption (BSFC) by $6 \%$ on average; along with a drop of $6 \%$ in $\mathrm{NO}_{\mathrm{X}}$ emission and $\mathrm{CO}$ emission is reduced by $19 \%$, comparing with B10. However, the presence of ethanol in fuel blend increases THC emission. Nevertheless, addition of Al@C nanoparticles reduces THC emission by $14.5 \%$ compared with B10E4. The emission of particles number (PN) is increased by 2.2 times for B10E4N30 on average but is reduced by $11.8 \%$ for B10E4 (adding ethanol only) on the contrary, compared to B10. The studies on morphology and phase structure of nanoparticles after combustion indicate that $\mathrm{Al} @ \mathrm{C}$ nanoparticles have been transformed into alumina nanoparticles.
\end{abstract}

Keywords: carbon-coated aluminum nanoparticles; diesel engine; performance; emissions.

3 The short version of the paper was presented at ICAE2017, Aug 21-24, Cardiff, UK. This paper is a substantial extension of the short version of the conferencepaper.

* Corresponding author.

E-mail address: yaodong.wang@ @ewcastle.ac.uk (Y.Wang).

\section{Introduction}

Confronted with the increase demand for more vehicles and the challenges to reduce energy/fuel consumption and emissions from engines to meet the stricter emission legislations, vehicle and engine manufacturers have been working hard on improving efficiency of energy use and reducing pollutant emissions in the last decades. There are three main methods for improving engine performance in terms of energy utilisation efficiency and reducing emissions: modification of combustion system, developing and using renewable alternative fuels and improving treatment of exhaust gases. Pirouzfar et al pointed out exhaust emissions arising from the fuel could be controlled by blending an oxygenated fuel (such as Methanol, Ethanol, and n-Butanol) with the diesel fuel, and engine performance could be improved at the same time [1]. A lot of research recognizes that adding biofuels can reduce some emissions with no or minor impact on engine performance, especially biodiesels [2-3]. Moreover, some researches reveal that adding various nanoparticles as nanocatalysts or nanoadditives in diesel or biodiesel-diesel blends can increase energy utilisation efficiency of engines by improving combustion efficiency and reduce exhaust emissions [4-5]. The most common nanoparticles used are metal and metal oxides, including aluminum, iron and silver [6-8], alumina [9-11], zinc oxide 
[12-13], titanium oxide [14-15], cerium oxide [16-17], iron oxide [18-19], and carbon nanotubes [20-21]. Some used are other kind of nanoadditives, such as cerium oxide nanoparticles and carbon nanotubes as mixed additives [22], cerium oxide with ferrocene nanoparticles [23], amorphous Ti-Al-B mixed metal nanopowders [24], manganese oxide [25], copper oxide [25] and nano-organic additives [26]. All these nanomaterials have been found being very useful to act as combustion catalyst to improve combustion behavior and reduce pollutant emissions because of their multifold enhancement in thermophysical and chemical properties of the modified fuels such as high surface to volume ratio, high reactive medium for combustion, high thermal conductivity to enhance heat and mass transport, improvement in flash point and so on [5].

On the other hand, core-shell structure nanoparticles, such as carbon coated metal or alloy nanoparticles have been attracted more and more research interests due to their unique structure [27-28]. Carbon coatings can not only protect metal core in ambient conditions and maintain excellent thermal properties, but also improve stability of suspension fuel because of its better hydrophilia than metals and metal oxides. However, few studies are found using carbon-coated-metal nanoparticles as additives. Therefore, it is necessary to carry out an investigation to study and understand the effect of adding carbon-coated-metal nanoparticles into diesel fuel blends on improving the energy utilisation efficiency (EUE) of engines and exhaust emissions. Due to $\mathrm{Al}$ or $\mathrm{Al}_{2} \mathrm{O}_{3}$ nanoparticles have been studied widely as fuel nanoadditive and show excellent ability on enhancement of EUE of engines as well as emission characteristics [6-7, 9-11], and it is known that aluminum has better thermal conductivity and lower density than most other metals which is beneficial to fuel suspension stability, carbon-coated-aluminum nanoparticles are selected as additive in this study.

\begin{tabular}{llll}
\multicolumn{2}{l}{ Nomenclature } & \\
Al@C & carbon coated aluminum & B20 & $20 \%$ biodiesel + 80\% diesel \\
B10 & $10 \%$ biodiesel + 90\% diesel & B50 & $50 \%$ biodiesel + 50\% diesel \\
B10E4 & $4 \%$ ethanol + 96\% B10 & B100 & $100 \%$ biodiesel \\
B10E4N30 $\quad 30 p p m$ nanoparticles + B10E4 & BMEP & brake mean effective pressure \\
BSFC & Brake specific fuel consumption & CO & Carbon monoxide \\
EDX & Energy Dispersive X-Ray Spectroscopy & ESC & European Stationary Cycle \\
EUE & Energy utilisation efficiency & HRTEM & High-resolution TEM \\
NOX & Nitrogen oxide & SEM & Scanning electron microscopy \\
THC & Total hydrocarbon compounds & TEM & Transmission electron microscopy \\
XPS & X-ray photoelectron spectroscope & \# & Number of particles
\end{tabular}

\section{Experimental method}

Biodiesel-diesel blends with various concentration of palm oil methyl ester (10, 20, 50 and $100 \%$ respectively) were selected as base fuels and named as B10 (10\% biodiesel $+90 \%$ diesel), B20 (20\% biodiesel $+80 \%$ diesel), B50 (50\% biodiesel $+50 \%$ diesel) and B100 (100\% biodiesel). As nanoparticles tend to disperse homogenously in ethanol, a small certain amount of carbon coated aluminum $(\mathrm{Al} @ \mathrm{C})$ nanoparticles at a dosage of 30ppm in mass fraction was dispersed in ethanol solution using ultrasonic bath for 30 minutes first. Then obtained nanoparticles-ethanol suspension was mixed with biodiesel-diesel blends under ultrasonic treatment for another 15 minutes at volume ratio of 4:96, without adding any surfactants. The morphologies and microstructures of $\mathrm{Al} @ \mathrm{C}$ nanoparticles before and after engine test was examined by transmission electron microscopy (TEM, JEOL JEM-2010HR) with energy dispersive X-ray spectroscopy (EDX, 
Thermo scientific ultra dry), X-ray photoelectron spectroscope (XPS, K-Alpha Thermo scientific) and field scanning electron microscopy (SEM, JEOL JEM-2100F ). For comparison, B10 blend fuel with 4\% ethanol was also prepared without adding nanoparticles, which was named as B10E4 (4\% ethanol $+96 \%$ B10).

The equipment and facilities used for the engine test included engine-performance test bench, exhaust gas analysers and a special designed filter rig to collect the particulates emitted from the engine. The engine performance, emission concentrations and the results of burned particles were recorded from their own data acquisition system. A heavy-duty diesel engine (Cummins ISBe5, it is an engine of four-cylinder in line, four-stroke with displacement of 4.5 liters) was used to carry out the tests to investigate the effect of target fuel blends. The engine parameters are listed in Table 1 in detail.

\begin{tabular}{ll}
\begin{tabular}{l} 
Table 1 Engine specifications. \\
\hline Type
\end{tabular} & $\begin{array}{l}\text { Cummins, four-cylinder, } \\
\text { four-stroke diesel engine }\end{array}$ \\
\hline Power (PS) & 207 \\
Peak torque (Nm) & 760 \\
Governed speed (rpm) & 2500 \\
Displacement (L) & 4.5 \\
Bore (mm) & 107 \\
& \\
Stroke (mm) & 124 \\
Cylinders & 4 \\
Emission & Euro 5 \\
Injection system & Common rail \\
& \\
Aspiration & Turbo-charged \\
Emission standard & Euro 5 \\
\hline
\end{tabular}

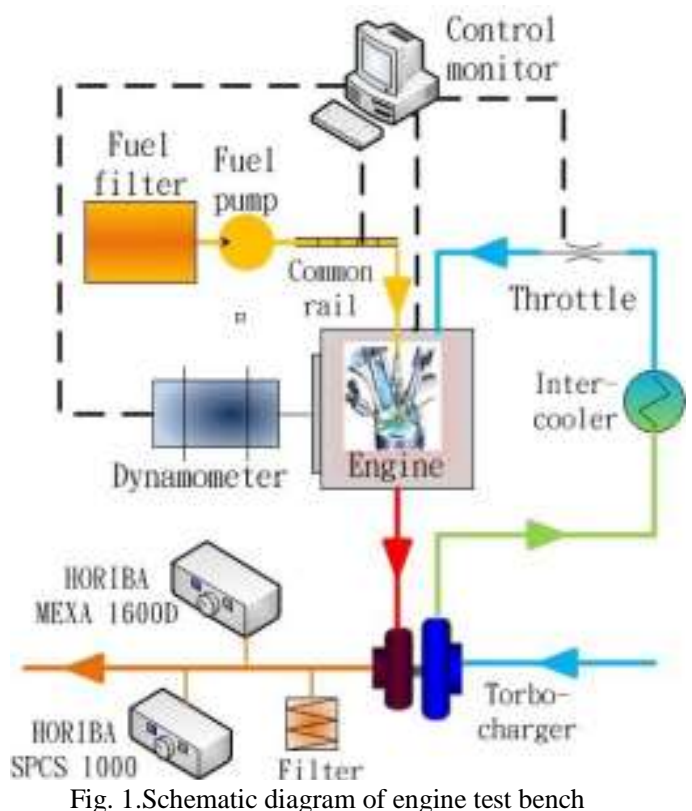

The engine had a common rail fuel injection system, which had a maximum value of 1800 bar pressure and one solenoid injectors for each cylinder, was shown in Fig. 1. The engine test-bench, the emission analysers, sensors and the data loggers were all calibrated before formal tests started, in order to ensure the accuracy of the data obtained. The experiments were undertaken according to the European Stationary Cycle (ESC) test cycle. The other parameters of working conditions were controlled by DaTAQ console. Subsequently, emissions characteristics, such as nitrogen oxide $\left(\mathrm{NO}_{\mathrm{X}}\right)$ emission, total hydrocarbon compounds (THC) and carbon monoxide (CO) emission, were recorded by Horiba MEXA 1600D. The value of emission particle numbers was measured by Horiba MEXA SPCS 1000 in real-time as well. Furthermore, in order to detect particles in the exhaust line, filter papers as track-etched polycarbonate membrane were used with 4 types of pore diameter from $10 \mu \mathrm{m}$ to $0.015 \mu \mathrm{m}$. When exhaust gas went through the four multiple filter papers, the particulates including combustion residues and other particles were adhering to filter paper in different scales. A vacuum pump was used in the filter papers' line to ensure that gas flew in one direction. These sample filtrations in this study were not only for particle removal, but also for particle collection in the further material analysis. TEM and XPS were employed to study the phase change and microstructure of nanoparticles embedded in the collected combustion residues on filter papers.

\section{Results and discussion}

The morphologies and microstructures of carbon coated aluminum nanoparticles were characterized by SEM and TEM 
$\mathrm{nm}$. The average particle size is around 120nm. It can be seen obviously from TEM observation that Al@C nanoparticles possess core-shell structure (Fig. 2b, c). The core-shell structure particles are quasi-spherical with diameter ranging from

$60 \mathrm{~nm}$ to $120 \mathrm{~nm}$, consistent with SEM observations. High-resolution TEM image in Fig. 2(c) display the disordered outer layer with thickness around $5 \mathrm{~nm}$, which indicating amorphous structure of graphite. It also reveals that the core is crystalline, having a calculated lattice spacing of $0.236 \mathrm{~nm}$, which consistent with the interlayer spacing corresponding to the (111) plane of face-centered cubic aluminum (JCPDS: 89-4037). The energy dispersive X-Ray spectroscopy (EDX)

results further confirm the nanoparticles contain a large amount of aluminum element, as shown in Fig. 2(d). The elemental mapping results from EDX demonstrate $\mathrm{Al}$ is evenly distributed in the nanoparticles with almost same density in all particles area, which could be observed from Fig. 2(e, f). Obviously, all the nanoparticles contain similar amount of aluminum as light spot representing the specific element spreads in the area that corresponds to the particles with mainly the same brightness. These observation results reveal that the nanoparticles have core-shell structure with aluminum cores surrounded by carbon shells completely. Core-shell structure of the nanoparticles with metallic core and carbon shell could improve suspension stability of the nanoparticles dispersed fuel, as metal tends be hydrophilic.
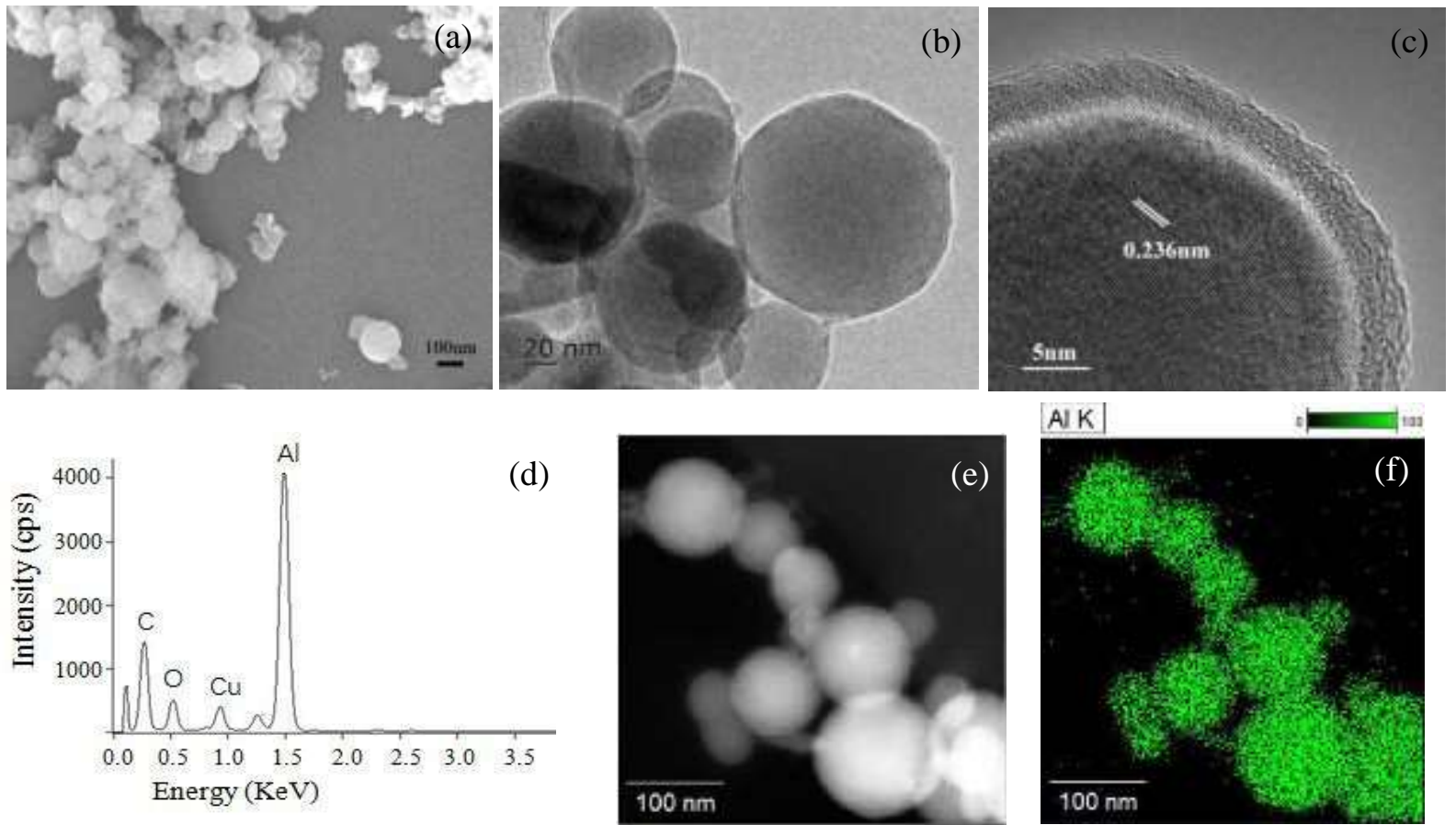

Fig. 2. SEM and TEM images of Al@Cnanoparticles.

(a) SEM image; (b) TEM image; (c) HRTEM image; (d) EDX result; (e-f) STEM-EDX image and corresponding elemental mapping of Al.

The sedimentation photographs of the prepared biodiesel-blend adding with $\mathrm{Al} @ \mathrm{C}$ nanoparticles without any surfactants before and after quiescence for 15 days are exhibited in Fig. 3. Four kinds of biodiesel-diesel blends with different palm oil methyl ester concentration are labeled as B10, B20, B50 and B100 for 10/90, 20/80, 50/50 and 100/0 respectively, corresponding to the ratio of biodiesel to diesel. Significantly, different agglomeration performance could be observed from four suspension blends samples. No obvious sedimentation is found for B10 sample added with Al@C nanoparticles. And a little agglomeration is observed for B20 suspension, whereas B50 and B100 sample display obvious sedimentation and leading to the emergence of original reddish-brown color from neat biodiesel. Further observation after 15 days later, it is found that B10 suspension sample kept stable and homogeneous, indicating its relatively good 
dispersion stability under the preparation process described above. It was thereby that the fuel blends of $30 \mathrm{ppm} \mathrm{Al} @ \mathrm{C}$ nanoparticles with $4 \%$ ethanol added into $10 \%$ palm oil-diesel (B10E4N30) was selected as the most suitable feedstock for the following engine tests.

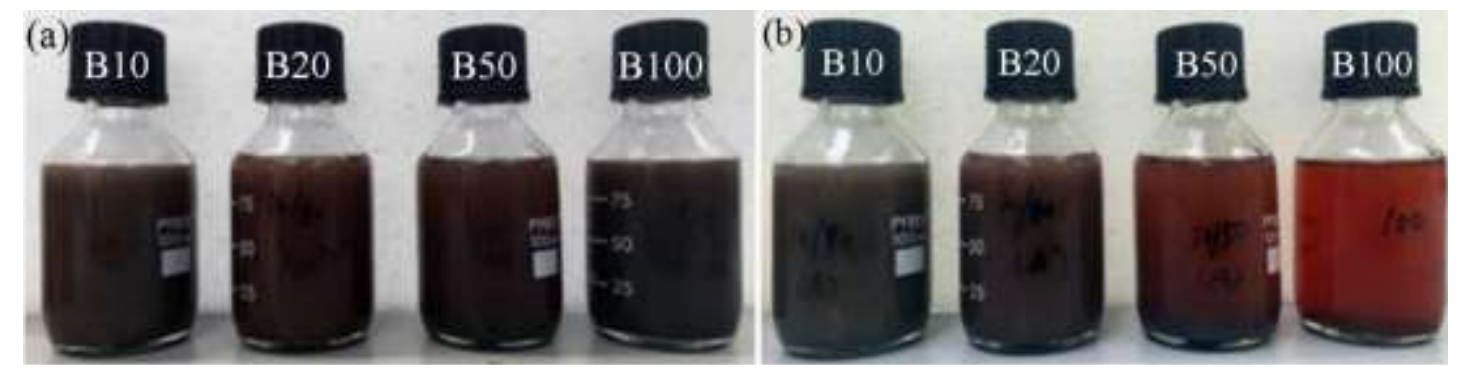

Fig. 3. Digital photographs of biodiesel-diesel suspension employing Al@C nanoparticles with various ratio of palm oil methyl ester. (a) Fresh prepared; (b) after quiescence for 15 days.

Three kinds of fuel blends were then prepared and used in the engine tests, including B10, B10E4 and B10E4N30, to compare the effect of Al@C nanoparticles on engine performance and emission characteristics. The variation of brake specific fuel consumption (BSFC) with brake mean effective pressure (BMEP) for all fuel samples is depicted in Fig. 4a. Clearly, as shown in Fig.4a, the BSFC value decrease along with increasing BMEP. It is apparent that the fuel consumption of B10E4N30 is lower than the other two samples which show basically the same behavior. As for B10E4N30, it contains only 30-ppm Al@C nanoparticles, therefore, the differences of the density and heat value of the three fuels are tiny and can be neglectable. The relative BSFC value ratios of B10E4 to B10 and B10E4N30 to B10 were calculated by normalizing B10 value as 1.0 for comparison. As noted from the Fig. 4b, B10E4N30 has the lowest value of BSFC in the whole ESC cycle, except for the mode 6. A distinct BSFC decrease for B10E4N30 is about 6\% on average in 12 modes under ESC condition, comparing with other two fuel blends. Meanwhile no obvious difference is found for the fuel consumption of B10E4 and B10.

Obviously, it should be carbon coated nanoparticles which can improve the combustion process and enhanced the thermal efficiency of the engine, which means that the homogeneous dispersion of $\mathrm{Al} @ \mathrm{C}$ nanoparticles in the fuel (B10E4N30) improves the spray atomisation of fuel when it is injected into the combustion chamber and improves combustion process. Therefore, more power output from the engine with the same amount of fuel input, and the BSFC reduced in the presence of $\mathrm{Al} @ \mathrm{C}$ nanoparticles. In diesel combustion process fuel is injected into hot air at the end of the compression process followed by auto-ignition and heat release. Hence fuel ignition and combustion qualities (e.g. fuel ignition delay and combustion period) in diesel engine have considerable effect on engine performance and exhaust gas composition. The ignition delay and combustion period are also strongly related to maximum combustion pressure, pressure rising rate and exhaust emissions. From the test results, it can be seen the engine performance (BSFS) are better than the original fuel when $\mathrm{Al} @ \mathrm{C}$ nanoparticles addedin.

The variation phenomenon is in accord with previous literature focused on aluminum nanoparticles where the BSFC for mixed diesel fuel with aqueous aluminum nanofluid is less than that of the diesel fuel at engine speeds less than 1800 rpm [6]. These results indicate clearly that $\mathrm{Al} @ \mathrm{C}$ nanoparticles play an important role in reducing the fuel consumption. 

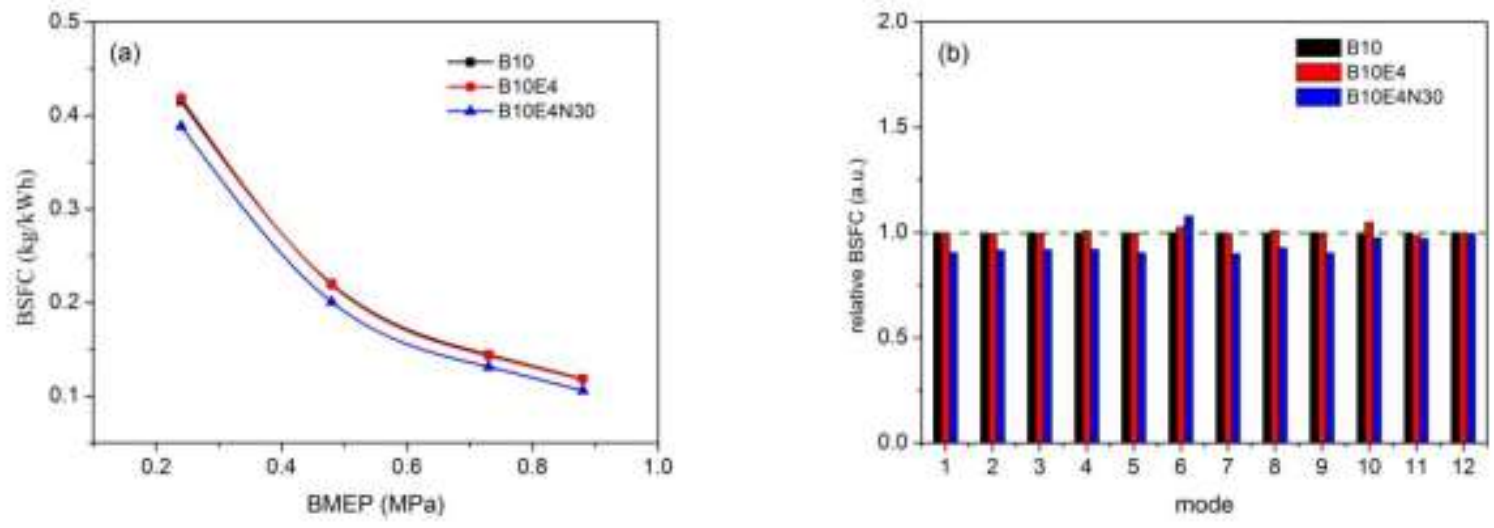

Fig. 4. Variation of brake specific fuel consumption (BSFC) (a) with BMEP; (b) relative BSFC in one ESC test cycle.

The test results of emission characteristics are displayed in Fig. 5 and Fig. 6. As can be seen from the graph in Fig. 5(a), nitrogen oxide emission continuously decrease with increase in BMEP, and the lowest value is $3.45 \mathrm{~g} / \mathrm{kWh}$ from B10E4N30. In terms of nitrogen oxide emission with BMEP, B10E4N30 is significantly less than the other two samples, while B10 and B10E4 exhibit almost the same except a slight reduction for B10E4 at around 0.9MPa. As shown in Fig. $5(\mathrm{~b})$, it is obviously that presence of $\mathrm{Al} @ \mathrm{C}$ nanoparticles results in the decline of $\mathrm{NO}_{\mathrm{X}}$ emission at 10 modes out of 12. An average drop of $6 \%$ in $\mathrm{NO}_{\mathrm{X}}$ emission is found in the whole ESC cycle when the engine was fueled with B10E4N30 as compared to B10. The maximum decrease is at point 2, approximately by $22 \%$. It is considered that aluminum nanoparticles could increase the surface area and reduces the ignition delay on one hand, the presence of Al@C nanoparticles help the active reaction of hydrocarbon with oxygen and reduces the reaction of nitrogen with oxygen on the other hand, which reduces the $\mathrm{NO}_{\mathrm{X}}$ formation in the cylinder [29]. Experimental study of aqueous aluminum nanofluid combustion in diesel fuel reveals that for engine speeds less than $1800 \mathrm{r} / \mathrm{min}$, the $\mathrm{NO}_{\mathrm{X}}$ concentration has also shown a decreasing trend [6]. As aluminum core in $\mathrm{Al} @ \mathrm{C}$ nanoparticles can be oxidized to alumina during engine combustion process, which may scramble for oxygen atoms with fuel, it is inferred that introduction of Al@C nanoparticles into biodiesel leads to not only reduces fuel consumption, but also reduces the emission levels of $\mathrm{NO}_{\mathrm{X}}$.
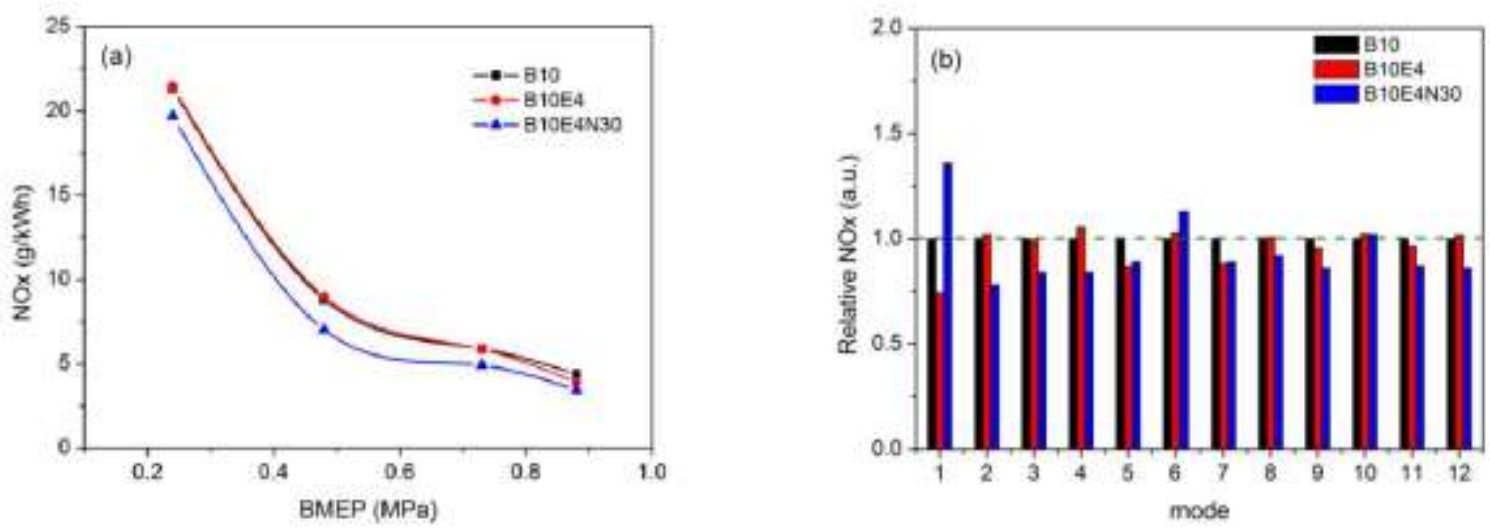

Fig. 5. Variation of Nitrogen oxide emission characteristics (a) with BMEP; (b) relative $\mathrm{NO}_{\mathrm{X}}$ emission in one ESC test cycle.

Fig. 6 represents the variation of $\mathrm{CO}$ and THC emission for three kinds of fuel blends. It is evident from the figure that 
B10E4 has the highest $\mathrm{CO}$ and THC emission values at almost all test modes from a diesel engine. Both $\mathrm{CO}$ and THC 60 emission from fuel blends B10E4 are raised to approximately 1.2 and 2.1 times as that of B10 respectively. It is generally 
considered that addition of the alcohols (such as ethanol) to the diesel fuel provides excess oxygen in the fuel blend that contributes the inner cylinder to produce $\mathrm{CO}$ and adds to the hydrocarbon amount as well [1]. However, significant decline of $19 \%$ in mean value of CO emission for B10E4N30 in the whole ESC cycle has been shown in Fig. 6b, comparing with B10. Taking into account the evident increase in $\mathrm{CO}$ emissions when ethanol is added alone in diesel-biodiesel blend and the apparent decrease in $\mathrm{CO}$ emissions when both ethanol and $\mathrm{Al} @ \mathrm{C}$ nanoparticles are added simultaneously, it is reasonable to believe that the $\mathrm{Al} @ \mathrm{C}$ nanoparticles can reduce diesel $\mathrm{CO}$ emissions effectively. The reduction of $\mathrm{CO}$ emissions due to the addition of nanoparticles may be attributed to the complete combustion of fuel, better atomization and extra surface energy provided by the nanoparticles [7, 15, 29]. For THC emission, as shown in Fig. 6c and 6d, it can be seen a significant increase in THC emission for the presence of ethanol (B10E4). But when A1@C nanoparticles added into B10E4, it reduced THC emission by $14.5 \%$ as compared to B10E4. It is thus clear that the Al@C nanoparticles can reduce THC emission, to a certain extent.
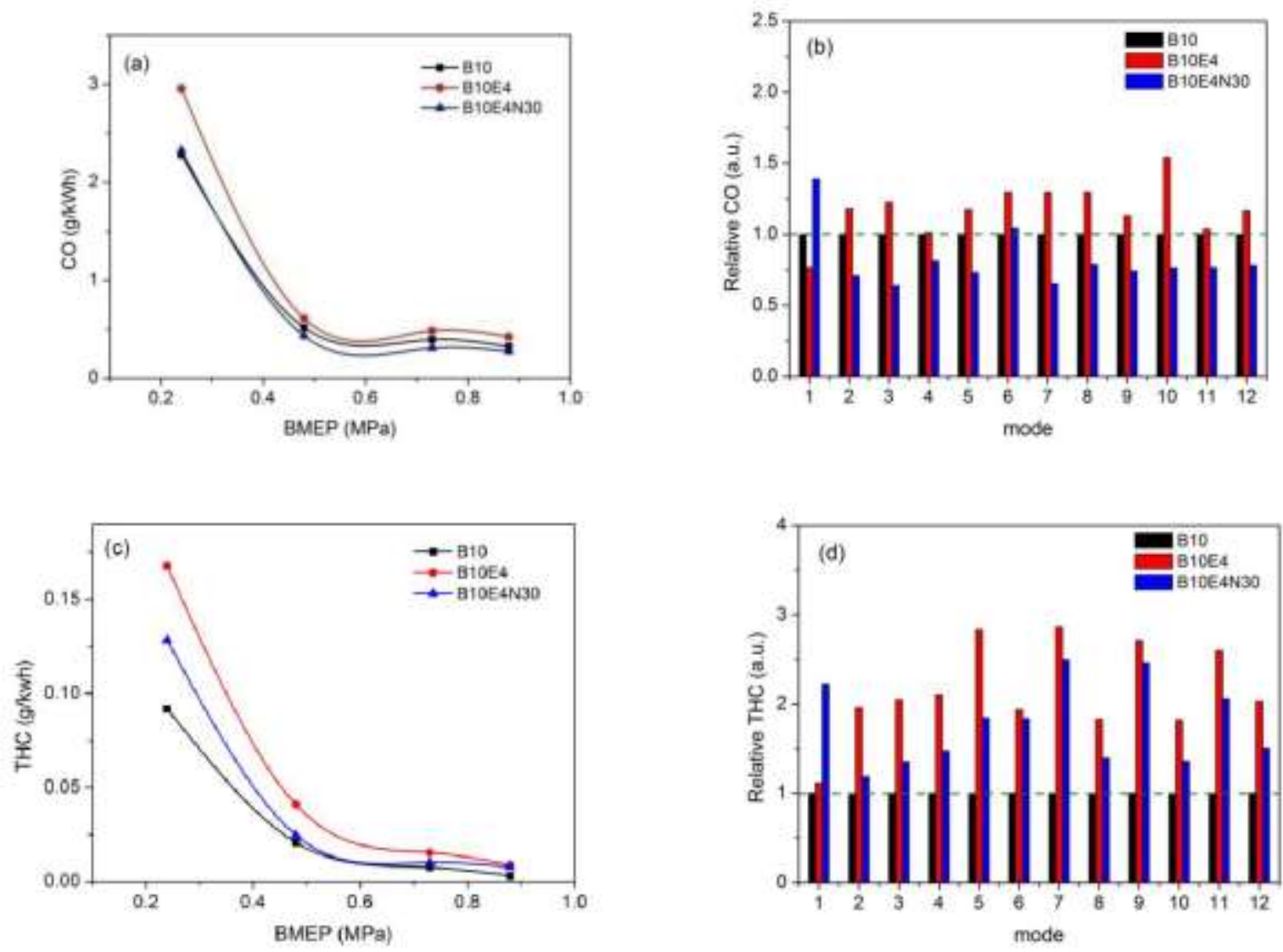

Fig. 6. Variation of $\mathrm{CO}$ and THC emission characteristics

(a) $\mathrm{CO}$ emission with BMEP; (b) relative $\mathrm{CO}$ emission in one ESC test cycle;

(c) THC emission with BMEP; (d) relative THC emission in one ESC test cycle.

Particle number concentration (PN) per unit $\mathrm{kWh}$ power output was used as the parameter for measurement of particulate emissions. The test results of the PN are shown in Fig. 7. The concentration of PN for B10E4N30 is the highest throughout the whole period, rising from around $4 \times 10^{6} \# / \mathrm{kWh}$ under around $0.5 \mathrm{MPa}$ to just over $11 \times 10^{6} \# /$ $\mathrm{kWh}$ at $0.9 \mathrm{MPa}$ BMEP condition. Fig. $7 \mathrm{~b}$ indicates a mean reduction of $11.8 \%$ in PN at the whole 12 test modes by adding $4 \%$ ethanol to diesel-biodiesel fuel blend (B10E4 compared to B10). Oxygenated fuels are known to reduce particulate matter emissions [1,3], since the alcohols contain oxygen and have lower ratio of carbon to hydrogen, the 
presence of ethanol cause the soot emissions reduced. However, significant increase of 2.2 times (mean value) in PN under ESC 12 mode condition for B10E4N30, comparing with B10. It has been reported in many literatures that the addition of nanoparticles can reduce smoke emission evaluated using value of smoke opacity [11, 15, 16, 20, 22]. Actually, particulate matter is a complex of diesel emissions which including carbonaceous particulate or soot and other organic solvents which adsorb the hydrocarbons [1, 21]. Zhang et al found both Ce- and Fe-doped fuels resulted in the formation of new particles with the nucleation mode within the peak diameters of $10-20 \mathrm{~nm}$, leading to an increase in the emission of total particle counts [23]. It is supposed that $\mathrm{Al} @ \mathrm{C}$ nanoparticles are burned totally during combustion process and formed alumina, which resulting to a distinct increase of emitted particles numbers.
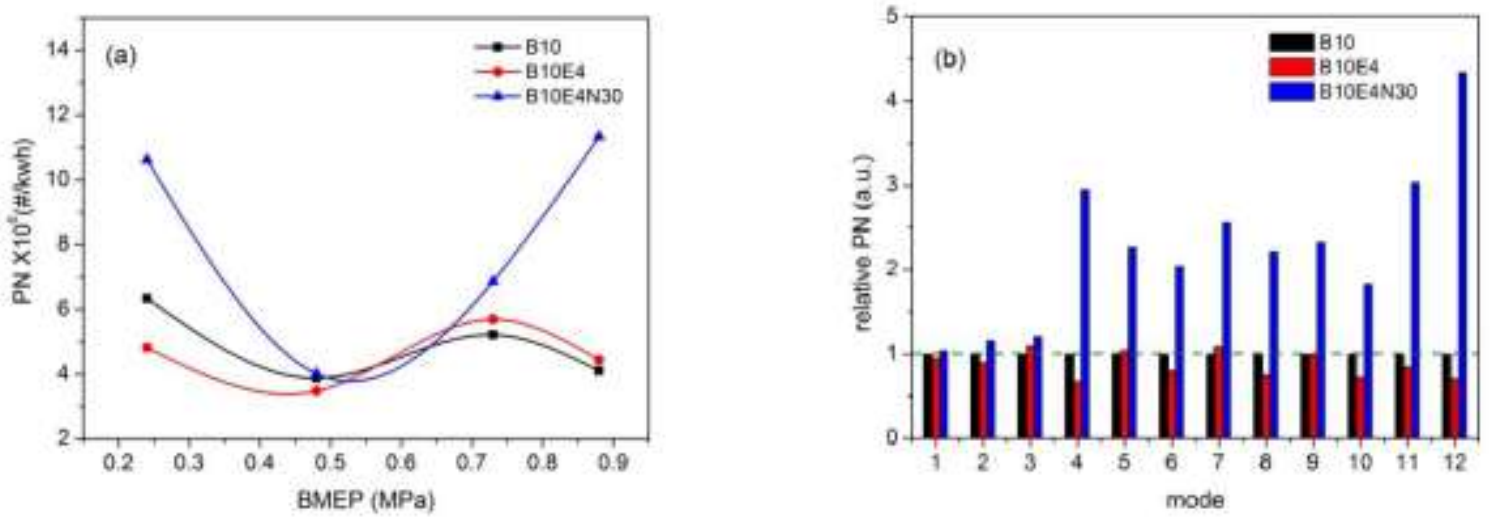

Fig. 7. Variation of PN values (a) with BMEP; (b) relative PN in one ESC test cycle.

In order to investigate the phase structure change of $\mathrm{Al} @ \mathrm{C}$ nanoparticles after engine test, the combustion residues collected from filter papers for B10E4N30 blend fuel were characterized by TEM. Spherical particle with about 160nm in diameter can be observed in Fig. 8a. However, the core-shell structure of nanoparticle is not very clear. EDX spectrum display the residues contain aluminum, oxygen, carbon and silicon. It is obvious both carbon and oxygen peak intensity relative to the aluminum peak increase after combustion, as comparison of Fig. 2(d) and Fig. 8(b). The calculated atomic percentage ratio of $\mathrm{Al} / \mathrm{O}$ from $\mathrm{EDX}$ spectrum is close to 2:3 which in keeping with the atom ratio in alumina $\left(\mathrm{Al}_{2} \mathrm{O}_{3}\right) . \mathrm{As}$ nanoparticles are embedded in combustion residues of biodiesel-diesel blends, the presence of Si and enlargement of $\mathrm{C}$ are attributed to the fuel residue. High-resolution TEM image (Fig. 8c) reveals that the nanoparticles are crystalline, and having calculated lattice spacing of $0.212 \mathrm{~nm}$ and $0.258 \mathrm{~nm}$ which are consistent with the (132) and (122) planes of orthorhombic $\mathrm{Al}_{2} \mathrm{O}_{3}$ (JCPDS: 88-0107). The corresponding SAED pattern (inset of Fig. 8c) further confirms the presence of the (013), (122) and (213) lattice planes of alumina.
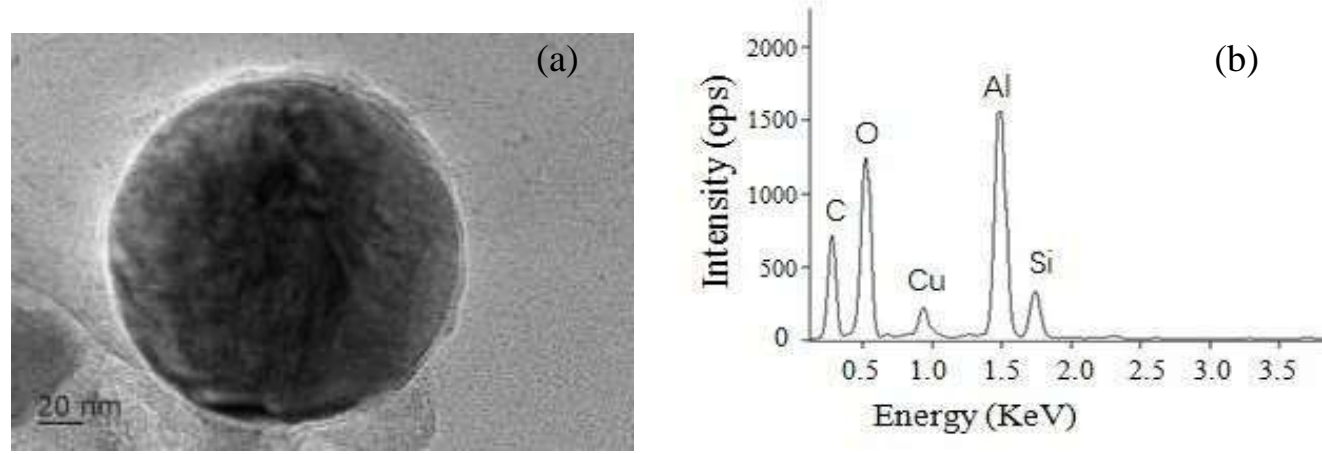


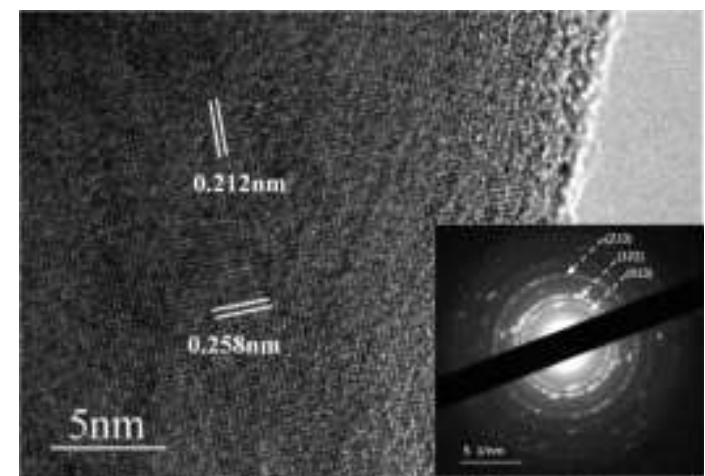

Fig. 8. TEM image of nanoparticles in collected combustion residue from B10E4N30 blend fuel.

(a) TEM image; (b) EDX; (c) HRTEM images of nanoparticles, the inset is corresponding SAEDpattern.

$\mathrm{X}$-ray photoelectron spectroscope (XPS) is a forceful tool to investigate the elemental composition as well as the oxidation states of elements. As shown in Fig. 9, the collected combustion residues contain C, O, N, Al, Si and S elementals, which is consistent with the EDX results. Two strong peaks at $284.9 \mathrm{eV}$ and $532.1 \mathrm{eV}$ are corresponding to $\mathrm{C} 1 \mathrm{~s}$ and $\mathrm{O} 1 \mathrm{~s}$ respectively. Since the detection area of XPS cannot be focused on the nanometer scale, the spectrum obtained is actually the average results from the surface of combustion residue containing nanoparticles. Therefore, the characteristic peak intensity of $\mathrm{Al}$ is relatively very weak, as shown in the inset of Fig. 9. And the appearance of Si and S characteristic peaks comes from chemical composition of diesel blends. The peak at $74.5 \mathrm{eV}$ can be calibrated as characteristic peak of $\mathrm{Al} 2 \mathrm{p}$ with a shift of $1.6 \mathrm{eV}$, indicating that aluminum atoms exist in the form of oxide rather than metal. Same result can be observed in the inset of Fig. 9, where the characteristic peak of $\mathrm{Al} 2 \mathrm{~s}$ at $119.3 \mathrm{eV}$ with a shift of $1.4 \mathrm{eV}$ relative to the metallic state. These results reveal clearly that $\mathrm{Al} @ \mathrm{C}$ nanoparticles have been transformed into alumina particles during combustion process in engine. And this transition may have a positive impact on both engine performance and $\mathrm{NO}_{\mathrm{X}}$ emission, but negative impact on $\mathrm{PN}$ emission. On the other hand, this may result in more ash accumulation in Diesel Particulate Filters (DPF) and affect the performance of the aftertreatment system and the engine itself. It may therefore be necessary to clean or change the aftertreatment system more frequently.

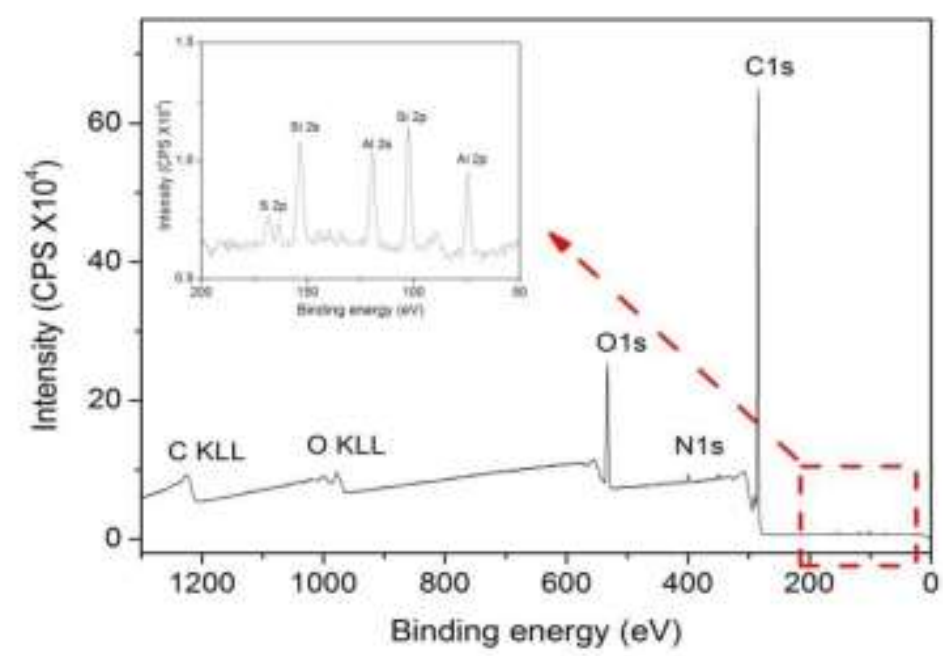

Fig. 9. XPS survey spectrum of collected combustion residue from B10E4N30 blend fuel, inset is magnified spectrum.

From the above results, it can be seen the characteristics of emissions from the diesel engine are changed, when Al@C 
nanoparticles added in. CO and THC emission are reduced significantly comparing with the presence of ethanol only. This can be explained as that better atomisation is achieved leading to reduction of fuel rich zone when homogeneous dispersion of Al@C nanoparticles added in the fuel; and the combustion process is improved which results in complete combustion of fuels. The reduction of $\mathrm{NO}_{\mathrm{X}}$ emission of $6 \%$ (average value) from $\mathrm{B} 10 \mathrm{E} 4 \mathrm{~N} 30$ is because the homogeneous $\mathrm{Al} @ \mathrm{C}$ nanoparticles are dispersed in the fuel and react with the oxygen quickly and predominately when it is injected into the combustion chamber and then form alumina and $\mathrm{CO}_{2}$, which surpass the reaction of nitrogen with oxygen during the combustion process. As a result, less $\mathrm{NO}_{\mathrm{X}}$ are formed; but more particles are formed in the combustion process and the particle numbers are increased significantly; and more ash is accumulated in Diesel Particulate Filters (DPF).

\section{Conclusions}

In summary, the performance and emission characteristics of a diesel engine fueled with diesel-biodiesel (10\%) blend, diesel-biodiesel blend with ethanol (4\%), and with both ethanol (4\%) and Al@C nanoparticles (30ppm) are experimentally investigated. Following conclusions can be drawn:

1) Stable and homogeneous fuel blends of diesel- biodiesel adding with Al@C nanoparticles and ethanol have been prepared successfully without any surfactant.

2) Improvement of engine performance is observed with lowered BSFC by $6 \%$ on average for the diesel-biodiesel blend with ethanol and $\mathrm{Al} @ \mathrm{C}$ nanoparticles, while little effect on BSFC is found for the diesel-biodiesel-ethanol blend.

3) A reduction in $\mathrm{NO}_{\mathrm{X}}$ emission of $6 \%$ on average is found for $\mathrm{B} 10 \mathrm{E} 4 \mathrm{~N} 30$, and along with an average drop of $19 \%$ in $\mathrm{CO}$ emission, compared to B10.

4) However, THC emission from B10E4 is much higher compared to B10; but the THC emission can be reduced when $\mathrm{Al} @ \mathrm{C}$ nanoparticles added in, compared to B10E4.

5) Significant increase on particle number concentration are found in the presence of $\mathrm{Al} @ \mathrm{C}$ nanoparticles.

6) $\mathrm{Al} @ \mathrm{C}$ nanoparticles are transformed into alumina nanoparticles during combustion process.

7) From the present work, it may conclude that adding Al@C nanoparticles in diesel-biodiesel blend provide an effective approach to improve engine performance by reducing BSFC and reduce $\mathrm{NO}_{\mathrm{X}}$ emissions. Further study is to be carried out to understand further the mechanism of the combined effect of nanoparticles and ethanol on the engine performance; and real application of the finding to improve the Energy utilisation efficiency of diesel engines.

\section{Acknowledgements}

This work was partly supported by the Science and Technology Planning Project of Guangdong Province, China (Grant No. 2015A050502047); Science and Technology Planning Project of Guangzhou City, China (Grant No. 2016201604030040); and EPSRC GLOBAL-Sustainable Energy through China-UK Research Engagement $(\mathrm{EP} / \mathrm{K} 004689 / 1)$

\section{References}

[1] Fayyazbakhsh A, Pirouzfar V. Comprehensive overview on diesel additives to reduce emissions, enhance fuel properties and improve engine performance. Renewable and Sustainable Energy Reviews 2017; 74: 891-901.

[2] Lapuerta M, Armas O, Rodrı' guez-Ferna' ndez J. Effect of biodiesel fuels on diesel engine emissions. Progress in Energy and Combustion Science 2008; 34: 198-223.

[3] Knothe G. Biodiesel and renewable diesel: A comparison. Progress in Energy and Combustion Science 2010; 36: $364-373$. 
[4] Shaafi T, Sairam K, Gopinath A, Kumaresan G, Velraj R. Effect of dispersion of various nanoadditives on the performance and emission characteristics of a CI engine fuelled with diesel, biodiesel and blends-A review. Renewable and Sustainable Energy Reviews 2015; 49:563-573.

[5] Saxena V, Kumar N, Saxena VK. A comprehensive review on combustion and stability aspects of metal nanoparticles and its additive effect on diesel and biodiesel fuelled C.I. engine. Renewable and Sustainable Energy Reviews 2017; 70: 563-588.

[6] Kao MJ, Ting CC, Lin BF, Tsung TT. Aqueous aluminum nano fluid combustion in diesel fuel. J Test Eval 2008;36:186-90.

[7] Mehta RN, Chakraborty M, Parikh PA. Nanofuels: combustion, engine performance and emissions. Fuel 2014; 120:91-7.

[8] Banapurmath N, Narasimhalu T, Hunshyat A, Sankaran R, Rabinal MH, Ayachit N, Kittur R. Effect of silver nano particle blended biodiesel and swirl on the performance of diesel engine combustion. Int J Sustain Green Energy 2014; 3(6):150-7.

[9] Shaafi T, Velraj R. Influence of alumina nanoparticles, ethanol and isopropanol blend as additive with diesel-soybean biodiesel blend fuel: Combustion, engine performance and emissions. Renewable Energy 2015; 80: 655-663.

[10] Hosseini SH, Taghizadeh-Alisaraei A, Ghobadian B, Abbaszadeh-Mayvan A. Effect of added alumina as nano-catalyst to diesel-biodiesel blends on performance and emission characteristics of CI engine. Energy 2017; 124: 543-552.

[11] Venu $\mathrm{H}$, Madhavan V.Effect of $\mathrm{Al}_{2} \mathrm{O}_{3}$ nanoparticles in biodiesel-diesel-ethanol blends at various injection strategies: Performance, combustion and emission characteristics. Fuel 2016;186:176-189.

[12] Selvaganapthy A, Sundar A, Kumaragurubaran B, Gopal P. An Experimental Investigation to Study the Effects of Various Nano Particles with Diesel on Di Diesel Engine. ARPN Journal of Science and Technology 2013; 3:112-115.

[13] Javed S, Murthy Y.V.V.S, Satyanarayana MRS, Reddy RR, Rajagopal K. Effect of a zinc oxide nanoparticle fuel additive on the emission reduction of a hydrogen dual-fuelled engine with jatropha methyl ester biodiesel blends. Journal of Cleaner Production 2016; 137: 490-506.

[14] Fangsuwannarak K, Triratanasirichai K. Improvements of palm biodiesel, properties by using nano-TiO ${ }_{2}$ additive, exhaust emission and engine performance. The Romanian Review Precision Mechanics, Optics \& Mechatronics 2013; 43:111-118.

[15] Nanthagopal K, Ashok B, Tamilarasu A, Johny A, Mohan A. Influence on the effect of zinc oxide and titanium dioxide nanoparticles as an additive with Calophyllum inophyllum methyl ester in a CI engine. Energy Conversion and Management 2017; 146: 8-19.

[16] Arul MozhiSelvan V, Anand RB, Udayakumar M. Effects of cerium oxide nanoparticle addition in diesel and diesel, biodiesel, ethanol blends on the performance and emission characteristics of a CI engine. ARPN Journal of Engineering and Applied Sciences 2009; 4:1-6.

[17] Mei D, Li X, Wu Q, Sun P. Role of Cerium Oxide Nanoparticles as Diesel Additives in Combustion Efficiency Improvements and Emission Reduction. J. Energy Eng., 2016, 142(4): 04015050.

[18] Shafii MB, Daneshvar F, Jahani N, Mobini K. Research article effect of ferrofluid on the performance and emission patterns of a four stroke diesel engine. Advances in Mechanical Engineering 2011; 529049.

[19] Sarvestany SN, Farzad A, Bajestan EE, Mir M. Effects of magnetic nanofluid fuel combustion on the performance and emission characteristics. J Dispers Sci Technol 2014; 35:1745-1750.

[20] Heydari-Maleney K, Taghizadeh-Alisaraei A, Ghobadian B, Abbaszadeh-Mayvan A. Analyzing and evaluation of carbon nanotubes additives to diesohol-B2 fuels on performance and emission of diesel engines. Fuel 2017; 196: 110-123.

[21] Hosseini S H, Taghizadeh-Alisaraei A, Ghobadian B, Abbaszadeh-Mayvan A. Performance and emission characteristics of a CI engine fuelled with carbon nanotubes and diesel-biodiesel blends. Renewable Energy 2017; 111: 201-213.

[22] Selvan VAM, Anand RB, Udayakumar M. Effect of Cerium Oxide Nanoparticles and Carbon Nanotubes as fuel-borne additives in Diesterol blends on the performance, combustion and emission characteristics of a variable compression ratio engine. Fuel 2014; 130: 160-167.

[23] Zhang ZH, Balasubramanian R. Effects of Cerium Oxide and Ferrocene Nanoparticles Addition as Fuel-Borne Catalysts on Diesel Engine Particulate Emissions: Environmental and Health Implications. Environ. Sci. Technol. 2017; 51, 4248-4258.

[24] Fisher BT, Cowart JS, Weismiller MR, Huba ZJ, Epshteyn A. Effects of Amorphous Ti-Al-B Nanopowder Additives on Combustion in a Single-Cylinder Diesel Engine. Journal of Engineering for Gas Turbines and Power 2017; 139: 092802.

[25] Lenin MA, Swaminathan MR, Kumaresan G. Performance and emission characteristics of a DI diesel engine with a nanofuel additive. Fuel 2013; 109:362-365.

[26] Yang WM, An H, Chou SK, Chua KJ, Mohan B, Sivasankaralingam V, Raman V, Maghbouli A, Li J. Impact of emulsion fuel with nano-organic additives on the performance of diesel engine. Applied Energy 2013; 112: 1206-1212.

[27] Zhang H, Wu Q, Lin J, Chen J, Xu Z. Thermal conductivity of polyethylene glycol nanofluids containing carbon coated metal nanoparticles. Journal of Applied Physics 2010; 108: 124304.

[28] Wu Q, Yu X, Zhang H, Chen Y, Liu L, Xie X, Tang K, Lu Y, Wang Y, Roskilly T. Fabrication and Thermal Conductivity Improvement of Novel Composite Adsorbents adding with Nanoparticles. Chinese Journal of Mechanical Engineering 2016; 29: 1114-1119.

[29] Debbarma S, Misra RD. Effects of Iron Nanoparticles Blended Biodiesel on the Performance and Emission Characteristics of a Diesel Engine. Journal of Energy Resources Technology 2017; 139:042212. 